\title{
NUTRIENTES E UMIDADE DO SOLO APÓS A INCORPORAÇÃO DE BIOCARVÃO EM UM PLANTIO DE Eucalyptus benthamii
}

\author{
SOIL NUTRIENTS AND MOISTURE AFTER INCORPORATING BIOCHAR IN AN \\ Eucalyptus benthamii FOREST
}

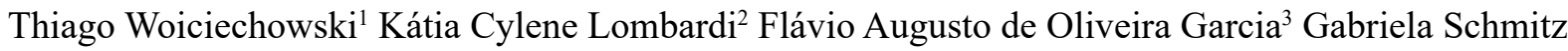
Gomes $^{3}$
\end{abstract}

\section{RESUMO}

O objetivo do trabalho foi avaliar as condições nutricionais e de umidade de um solo cultivado com $E u$ calyptus benthamii no qual se incorporou biocarvão oriundo da pirólise rápida de uma mistura de madeiras de espécies nativas de Floresta Ombrófila Mista no preparo pré-plantio. O estudo foi desenvolvido em área experimental do Campus da Universidade Estadual do Centro-Oeste, localizada em Irati, Paraná. Foram utilizadas quatro doses de biocarvão, $0,10,20$ e $40 \mathrm{Mg} \mathrm{ha}^{-1}$, com e sem adubação mineral de $340 \mathrm{Kg} \mathrm{ha} \mathrm{Ka}^{-1}$ de NPK com $14 \mathrm{Kg}$ de N, $48 \mathrm{Kg}$ de $\mathrm{P}_{2} \mathrm{O}_{5}, 28 \mathrm{Kg}$ de $\mathrm{K}_{2} \mathrm{O}$ no formulado 4-14-8, em delineamento em blocos ao acaso com quatro repetições. As mudas de Eucalyptus benthamii foram plantadas em espaçamento 3 por 2 metros e após 60 e 180 dias foram avaliados os seguintes atributos do solo: pH, carbono orgânico, teores de $\mathrm{P}, \mathrm{K}, \mathrm{Ca}, \mathrm{Mg}$, Al e a umidade do solo. A aplicação de $40 \mathrm{Mg}$ ha $^{-1}$ de biocarvão com e sem adubação de base ocasionou aumento do $\mathrm{pH}$ e nutrientes devido ao teor de cinzas na constituição do condicionador, e aumento da umidade do solo. A aplicação de biocarvão pode se tornar uma prática positiva com o objetivo de disponibilizar nutrientes para o desenvolvimento inicial da cultura. Entretanto, deve-se a avaliar o efeito da fertilidade, de acordo com as doses aplicadas, uma vez que a disponibilidade de nutrientes diminuiu ao longo do tempo acarretando a necessidade de adubações de cobertura, porém em quantidades menores.

Palavras-chave: fertilidade do solo; cinzas; Eucalipto.

\section{ABSTRACT}

The objective of this research was to evaluate the nutritional and moisture conditions of a soil cultivated with Eucalyptus benthamii, in which it was used biochar coming from the fast pyrolysis of a mixture of native species of Mixed Ombrophilous Forest in the preparation of the pre-planting. The study was developed in an experimental area of the State University of the Center-West located in Irati, Parana state. Four doses of biochar, $0,10,20$ and $40 \mathrm{Mg} \mathrm{ha}^{-1}$, with and without mineral fertilization of $340 \mathrm{Kg} \mathrm{ha}^{-1}$ of NPK with $14 \mathrm{Kg} \mathrm{N}, 48 \mathrm{Kg} \mathrm{P}_{2} \mathrm{O}_{5}, 28 \mathrm{Kg} \mathrm{K}_{2} \mathrm{O}$ in formulation 4-14-8, in a randomized complete block design with four replicates. Eucalyptus benthamii seedlings were planted in spacing 3 × 2 meters and, after 60 and 180 days, the following soil attributes were evaluated: $\mathrm{pH}$, organic carbon, $\mathrm{P}, \mathrm{K}, \mathrm{Ca}, \mathrm{Mg}, \mathrm{Al}$ contents and soil moisture. The application of $40 \mathrm{Mg} \mathrm{ha}^{-1}$ biochar with and without basic fertilization, caused an increase of $\mathrm{pH}$ and nutrients due to the ash content in the constitution of the conditioner, and an increase of the soil moisture. The application of biochar may become a positive practice in order to provide nutrients for the initial development of the crop. However, it is necessary to evaluate the effect of fertility according to

1 Engenheiro Florestal, Dr., Professor do curso de Engenharia Florestal, Universidade Estadual de Mato Grosso do Sul, Unidade Universitária de Aquidauana, Rod. Graziela Maciel Barroso, Km 12, CEP 79200-000, Aquidauana (MS), Brasil. thiagowoi@uems.br

2 Engenheira Agrônoma, Dra ${ }^{\text {. }}$, Professora do Departamento de Engenharia Florestal, Setor de Ciências Agrárias e Ambientais, Universidade Estadual do Centro-Oeste, PR 153, Km 7, Riozinho, CEP 84500-000, Irati (PR), Brasil. kclombardi@unicentro.br

3 Engenheiro Florestal, Dr., Professor do Departamento de Engenharia Florestal, Setor de Ciências Agrárias e Ambientais, Universidade Estadual do Centro-Oeste, PR 153, Km 7, Riozinho, CEP 84500-000, Irati (PR), Brasil. fgarcia.unicentro@gmail.com / profagabrielaflorestal@yahoo.com.br 
the dose applied, since the availability of nutrients may decrease over time, leading to the need for cover fertilization, however in smaller amounts.

Keywords: soil fertility; ash; Eucalyptus.

\section{INTRODUÇÃO}

Estudos com foco no carvão de biomassa florestal incorporado nos solos estão em voga. Trabalhos envolvendo as Terras Pretas de Índio (TPI), que são solos que ocorrem na região Amazônica, caracterizados por alta fertilidade devido ao acúmulo de biocarvão formados a partir da ação pirogênica e depositados nesses solos por populações indígenas (LEHMANN; JOSEPH, 2009) são referências.

O carvão pirogênico é resultante da combustão parcial dos materiais, originando uma matéria orgânica estável e resistente à degradação química, térmica e fotoquímica. A estrutura química do carvão confere estabilidade e reatividade de acordo com o tempo de aplicação, e sua estrutura aromática, alifática, hidrofóbica e seus grupos funcionais ácidos, formados através da oxidação biológica lenta, resultam em acumulação e persistência do carbono no solo e retenção e disponibilidade de nutrientes (MADARI et al., 2006). O termo biochar (biocarvão) foi criado para descrever a aplicação de matéria orgânica carbonizada ao solo em uma forma deliberada, para melhorar as propriedades do solo ou para armazenar carbono (LEHMANN; JOSEPH, 2009). Durante o processo denominado de pirólise rápida (temperatura entre 450$550^{\circ} \mathrm{C}$ ) há a formação de biocarvão com baixa granulometria que transforma cerca da metade do carbono armazenado no tecido vegetal em uma forma estável e inativa de carbono. Este processo complementa o processo da fotossíntese, que remove o $\mathrm{CO}_{2}$ da atmosfera através de mecanismos fisiológicos das plantas, enquanto a aplicação de biocarvão no solo estoca o carbono de forma sólida, também benéfica (MAIA, 2012).

Assim como ocorreu nas TPI, a aplicação de diferentes tipos de biocarvão tem sido relatada em diversas tipologias de solos e culturas agrícolas com resultados promissores com relação à melhoria na fertilidade do solo, aos aspectos físicos e com ganhos de produtividade. A presença do biocarvão pode contribuir para mudanças significativas nas propriedades físicas e químicas do solo, alterando características tais como: textura, estrutura, porosidade, diâmetro dos poros, distribuição granulométrica, densidade, $\mathrm{pH}$ do solo, disponibilidade de nutrientes, aumento do teor de matéria orgânica e redução da concentração de metais pesados (GLASER; LEHMANN; ZECH, 2002; LEHMANN; RONDON, 2006; MEDEIROS JUNIOR, 2007; HOSSAIN et al., 2010; PETTER, 2010; SOHI, 2010; SMIDER; SINGH, 2014; OJEDA et al., 2015; PUGA et al., 2015). Em culturas florestais, estudos relacionados à incorporação de biocarvão em solos ainda são incipientes, com poucos resultados em relação à produtividade e ao manejo da adubação e do solo. Assim, este estudo teve como objetivo avaliar a disponibilidade de nutrientes, acidez e a umidade do solo devido à aplicação de diferentes doses de biocarvão no pré-plantio em reflorestamento com $E u$ calyptus benthamii.

\section{MATERIAL E MÉTODOS}

O experimento foi conduzido no município de Irati no Paraná $\left(25^{\circ} 27^{\prime} \mathrm{S} ; 50^{\circ} 37^{\prime} \mathrm{W}\right.$ e altitude de 890 metros), durante o ano de 2010. O clima da região, segundo a classificação de Köppen, é classificado como $\mathrm{Cfb}$. O solo utilizado classifica-se como Cambissolo Háplico Ta Distrófico típico (EMBRAPA, 2006) de textura muito argilosa com $647 \mathrm{~g} \mathrm{dm}^{-3}$ de argila. A pluviosidade média nos meses de realização do ensaio no município de Irati é apresentada na Tabela 1. 
TABELA 1: Precipitações pluviométricas mensais, em milímetros, núcleo regional de Irati-PR (SECRETARIA DO ESTADO E DO ABASTECIMENTO DO PARANÁ, 2011).

TABLE 1: Monthly rainfall in millimeters, regional nucleus of Irati, Paraná state (SECRETARIA DO ESTADO E DO ABASTECIMENTO DO PARANÁ, 2011).

\begin{tabular}{ccccccccccc}
\hline Jan-10 & Fev-10 & Mar-10 & Abr-10 & Mai-10 & Jun-10 & Jul-10 & Ago-10 & Set-10 & Out-10 & Nov-10 \\
227,5 & 173,4 & 299,6 & 345,2 & 91,4 & 83,4 & 132,2 & 58,0 & 68,2 & 263,8 & 92,4 \\
\hline
\end{tabular}

Para a realização do ensaio procedeu-se o preparo do solo em que inicialmente aplicou-se $2,5 \mathrm{Mg}$ ha $^{-1}$ de calcário dolomítico $(29 \%$ de $\mathrm{CaO}$ e $20 \%$ de $\mathrm{MgO})$ a lanço, com posterior incorporação com grade leve nos $20 \mathrm{~cm}$ superficiais do solo. Aguardou-se um mês e procedeu-se a aplicação a lanço e em área total do biocarvão com incorporação com gradagem leve. O biocarvão é proveniente de um depósito com volume expressivo, a céu aberto, de uma área de assentamento de famílias de pequenos agricultores pelo INCRA (Instituto Nacional de Colonização e Reforma Agrária), na cidade de Inácio Martins, Paraná, denominado Assentamento José Dias. A ocupação da área pelos assentados ocorreu em 1988 e a partir de 1998 iniciou-se a produção de carvão utilizando as espécies de canela (Ocotea $\mathrm{sp}$ ), bracatinga (Mimosa scrabella Hoehne) e resíduos de imbuia (Ocotea porosa (Nees \& C. Mart.) Barroso), cortados com o objetivo de abertura de área para a exploração agrícola. Os tratamentos foram constituídos de três diferentes doses de biocarvão aplicados no solo sem adubação de base e das mesmas doses com a adubação de base (Tabela 2).

TABELA2: Descrição dos tratamentos utilizados para a realização do ensaio, com as doses de biocarvão incorporadas na camada de $20 \mathrm{~cm}$ do solo e adubação aplicada em coveta na lateral das mudas plantadas.

TABLE 2: Description of treatments used for the assay, with doses of biochar incorporated in the layer of $20 \mathrm{~cm}$ of the soil and fertilizer applied in a hole beside the planted seedlings.

\begin{tabular}{cc}
\hline Tratamento & Descrição \\
\hline T1 & Sem biocarvão; sem adubação de base \\
T2 & $10 \mathrm{Mg} \mathrm{ha}^{-1}$ de biocarvão; sem adubação de base \\
T3 & $20 \mathrm{Mg} \mathrm{ha}^{-1}$ de biocarvão; sem adubação de base \\
T4 & $40 \mathrm{Mg} \mathrm{ha}^{-1}$ de biocarvão; sem adubação de base \\
T5 & Sem biocarvão; com adubação de base $_{\text {T6 }}$ \\
T7 & $10 \mathrm{Mg} \mathrm{ha}^{-1}$ de biocarvão; com adubação de base \\
T8 & $20 \mathrm{Mg} \mathrm{ha}^{-1}$ de biocarvão; com adubação de base \\
\hline
\end{tabular}

A adubação de base consistiu-se de $340 \mathrm{Kg} \mathrm{ha}^{-1}$ de NPK com $14 \mathrm{Kg}$ de N, $48 \mathrm{Kg}$ de $\mathrm{P}_{2} \mathrm{O}_{5}, 28 \mathrm{Kg}$ de $\mathrm{K}_{2} \mathrm{O}$ no formulado 4-14-8, aplicados em covetas laterais. Após o preparo do solo procedeu-se o plantio das mudas de Eucalyptus benthamii, utilizando-se um espaçamento 3 por 2 metros, realizado no mês de março de 2010. Utilizou-se o delineamento em blocos casualizados com 4 blocos. A área útil das parcelas experimentais foi de $288 \mathrm{~m}^{2}$, com um total de 48 plantas por parcela. As características do biocarvão utilizado no ensaio foram $\mathrm{pH}$ em $\mathrm{H}_{2} \mathrm{O}$ de 4,$9 ; 79 \%$ de granulometria inferior a $2 \mathrm{~mm} ; 5 \%$ de umidade; $26 \%$ de teor de voláteis e de cinzas e 48\% de carbono fixo (EMBRAPA, 1997; Norma da ASTM D-1762-84 adaptada por OLIVEIRA et al., 1982).

Aos 60 e 180 dias após o plantio foram coletadas amostras de solo com o auxílio de um trado holandês em cinco pontos dentro de cada parcela na profundidade 0-20 cm. Estas amostras foram misturadas para compor uma amostra composta representando o solo da parcela. Após, levou-se o material para laboratório de Solos Florestais da Universidade Estadual do Centro-Oeste e, posteriormente, secaram-se as 
amostras em estufa $\mathrm{a} \pm 60^{\circ} \mathrm{C}$, seguindo o destorroamento e peneiramento em peneira com malha $2 \mathrm{~mm}$ de abertura. Assim, alíquotas dessas amostras foram retiradas para a realização de análises químicas em que se avaliaram: $\mathrm{pH}$ e acidez potencial, por potenciometria determinada na suspensão do solo após agitação e decantação; matéria orgânica pelo método de Walkley-Black; P por espectrofotômetro ultravioleta visível; K por fotômetro de chama, e $\mathrm{Ca}, \mathrm{Mg}$ e $\mathrm{Al}$ por titulometria. Em relação às análises físicas do solo, avaliou-se a umidade do solo por coletas de amostras indeformadas com o auxílio de anel de Kopecky na profundidade 0-10 cm e determinação dos valores de umidade do solo (Ug) seguindo a metodologia da Embrapa (1997). A análise de variância foi realizada com o auxílio do software ASSISTAT ${ }^{\circledR}$ versão 7.6 beta (SILVA; AZEVEDO, 2002), usando-se o teste de Tukey para comparação de médias quando pertinentes.

\section{RESULTADOS E DISCUSSÃO}

\section{Resultados dos tratamentos nos teores de nutrientes, acidez e umidade do solo}

Foram observadas diferenças em relação à testemunha para os nutrientes, acidez e umidade do solo após a aplicação do biocarvão, sendo que ocorreram variações em relação ao atributo avaliado e o tempo, dado em dias, após a aplicação do tratamento (Tabela 3).

TABELA 3: Valores médios para $\mathrm{pH}$, acidez potencial $(\mathrm{H}+\mathrm{Al})$, carbono $(\mathrm{C})$, fósforo $(\mathrm{P})$, potássio $(\mathrm{K})$ cálcio $(\mathrm{Ca})$, magnésio (Mg), alumínio (Al), e percentual de umidade do solo (Ug) para os tratamentos aos 60 e 180 dias após a incorporação do biocarvão em plantio de Eucalyptus benthamii, em Irati-PR.

TABLE 3: Mean values for $\mathrm{pH}$, potential acidity $(\mathrm{H}+\mathrm{Al})$, carbon $(\mathrm{C})$, phosphorus $(\mathrm{P})$, potassium $(\mathrm{K})$ calcium $(\mathrm{Ca})$, magnesium $(\mathrm{Mg})$, aluminum $(\mathrm{Al})$ and soil moisture $(\mathrm{Ug})$ of the treatments at 60 and 180 days after the incorporation of biochar in a forest of Eucalyptus benthamii in Irati, Paraná state.

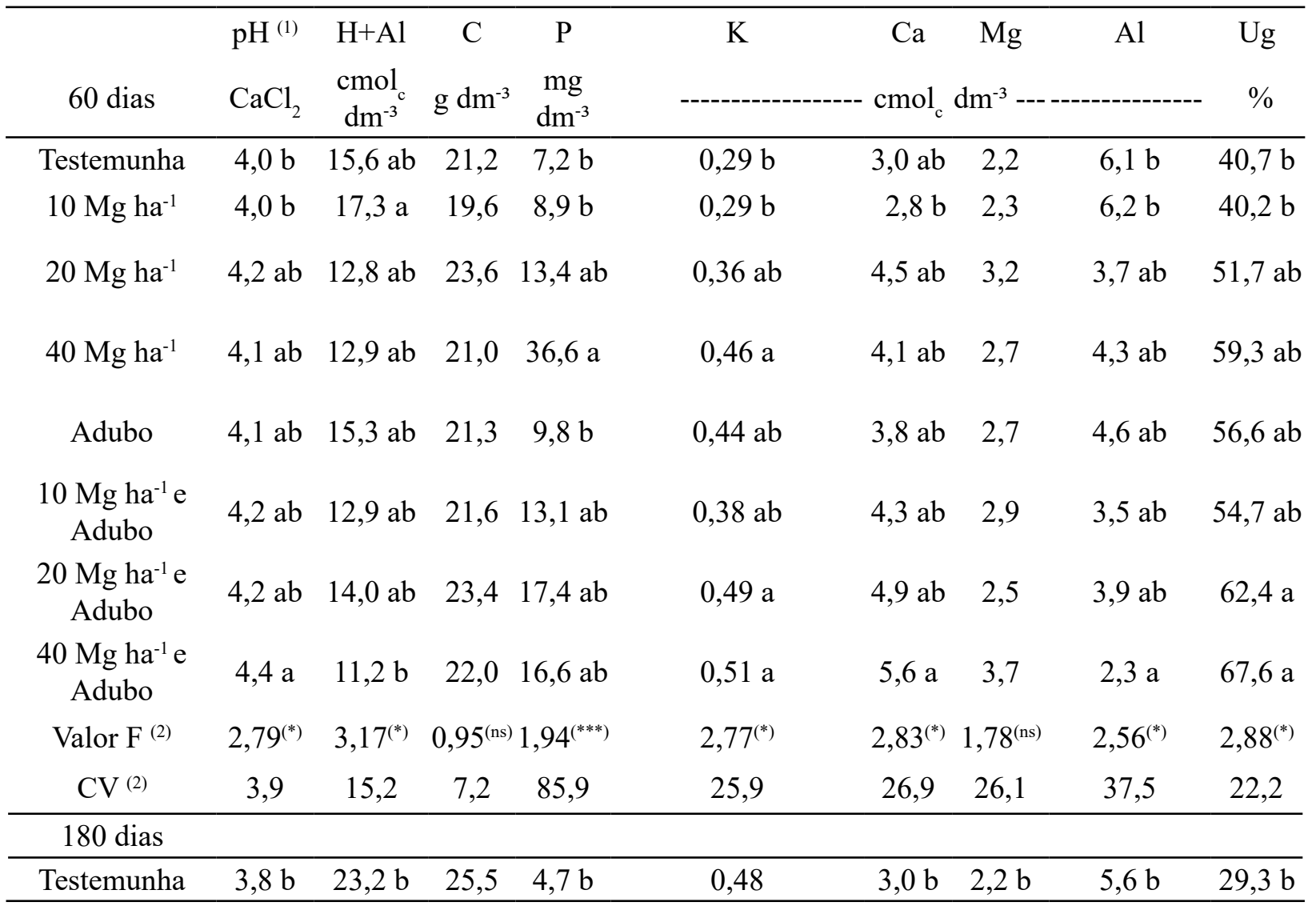


TABELA 3: Continuação...

TABLE 3: Continued..

\begin{tabular}{|c|c|c|c|c|c|c|c|c|c|}
\hline 180 dias & $\begin{array}{l}\mathrm{pH}^{(1)} \\
\mathrm{CaCl}_{2}\end{array}$ & $\begin{array}{c}\mathrm{H}+\mathrm{Al} \\
\mathrm{cmol}_{\mathrm{c}} \\
\mathrm{dm}^{-3}\end{array}$ & $\begin{array}{c}\mathrm{C} \\
\mathrm{g} \mathrm{dm}{ }^{-3}\end{array}$ & $\begin{array}{c}\mathrm{P} \\
\mathrm{mg} \\
\mathrm{dm}^{-3}\end{array}$ & K & $\begin{array}{c}\mathrm{Ca} \\
-\mathrm{cmol}_{\mathrm{c}}\end{array}$ & $\begin{array}{r}\mathrm{Mg} \\
\mathrm{dm}^{-3}--\end{array}$ & ----- & $\begin{array}{l}\mathrm{Ug} \\
\%\end{array}$ \\
\hline $10 \mathrm{Mg} \mathrm{ha}^{-1}$ & $4,0 \mathrm{~b}$ & $18,2 \mathrm{ab}$ & 24,4 & $7,2 \mathrm{ab}$ & 0,51 & $3,7 a b$ & $2,8 \mathrm{ab}$ & $4,1 \mathrm{ab}$ & $41,4 \mathrm{ab}$ \\
\hline $20 \mathrm{Mg} \mathrm{ha}^{-1}$ & $4,0 \mathrm{~b}$ & $19,6 \mathrm{~b}$ & 25,5 & $6,0 \mathrm{ab}$ & 0,50 & $4,0 \mathrm{ab}$ & $3,1 \mathrm{ab}$ & $3,7 \mathrm{ab}$ & $41,1 \mathrm{ab}$ \\
\hline $40 \mathrm{Mg} \mathrm{ha}^{-1}$ & $4,1 \mathrm{ab}$ & $16,1 \mathrm{ab}$ & 25,5 & $10,6 \mathrm{a}$ & 0,50 & $4,8 \mathrm{ab}$ & $2,7 \mathrm{ab}$ & $3,6 \mathrm{ab}$ & $46,5 \mathrm{a}$ \\
\hline Adubo & $3,8 \mathrm{ab}$ & $21,1 \mathrm{~b}$ & 25,2 & $4,7 \mathrm{~b}$ & 0,49 & $3,3 \mathrm{~b}$ & $2,7 \mathrm{ab}$ & $5,4 \mathrm{~b}$ & $40,6 \mathrm{ab}$ \\
\hline $\begin{array}{c}10 \mathrm{Mg} \mathrm{ha}^{-1} \mathrm{e} \\
\text { Adubo }\end{array}$ & $3,9 \mathrm{~b}$ & $20,4 \mathrm{~b}$ & 24,3 & $5,2 \mathrm{ab}$ & 0,62 & $4,1 \mathrm{ab}$ & $2,3 \mathrm{~b}$ & $4,5 a b$ & $40,5 \mathrm{ab}$ \\
\hline $\begin{array}{c}20 \mathrm{Mg} \mathrm{ha}^{-1} \mathrm{e} \\
\text { Adubo }\end{array}$ & $4,1 \mathrm{ab}$ & $18,3 \mathrm{ab}$ & 26,7 & $6,5 \mathrm{ab}$ & 0,54 & $4,6 a b$ & $3,3 \mathrm{ab}$ & $2,9 a b$ & $39,5 \mathrm{ab}$ \\
\hline $\begin{array}{c}40 \mathrm{Mg} \mathrm{ha}^{-1} \mathrm{e} \\
\text { Adubo }\end{array}$ & $4,4 \mathrm{a}$ & $12,2 \mathrm{a}$ & 27,3 & $11,2 \mathrm{a}$ & 0,62 & $6,5 \mathrm{a}$ & $4,0 \mathrm{a}$ & $1,8 \mathrm{a}$ & $44,2 \mathrm{a}$ \\
\hline Valor F & $4,69^{(* *)}$ & $6,18^{(* *)}$ & $0,54^{(\mathrm{ns})}$ & $2,46^{(* * *)}$ & $1,03^{(\mathrm{ns})}$ & $3,35^{(*)}$ & $3,27^{(*)}$ & $3,23^{(*)}$ & $2,68^{(*)}$ \\
\hline $\mathrm{CV}$ & 4,3 & 13,7 & 6,6 & 47,6 & 21,1 & 27,9 & 22,6 & 35,1 & 17,7 \\
\hline
\end{tabular}

Em que: ${ }^{1}=\mathrm{pH}, \mathrm{H}+\mathrm{Al}, \mathrm{C}, \mathrm{P}, \mathrm{K}, \mathrm{Ca}, \mathrm{Mg}, \mathrm{Al}$, e Ug são respectivamente: potencial hidrogeniônico, acidez potencial, carbono orgânico do solo, fósforo, potássio, cálcio, magnésio, alumínio, umidade gravimétrica do solo. Médias seguidas pela mesma letra não diferem estatisticamente pelo teste de Tukey; ${ }^{(*)} 5 \%$ de probabilidade; ${ }^{(* *)} 1 \%$ de probabilidade, ${ }^{(* *)} 10 \%$ de probabilidade e ${ }^{(n)}$ - não significativo ${ }^{2}=$ Valor de $\mathrm{F}$ obtido pelo teste da ANOVA e CV - coeficiente de variação em porcentagem.

Os parâmetros acidez potencial, carbono e magnésio não diferiram do tratamento controle na avaliação aos 60 dias após o plantio. Com relação aos parâmetros $\mathrm{pH}$, potássio, alumínio e umidade do solo nessa avaliação apenas o tratamento $40 \mathrm{Mg}$ ha $^{-1}$ de carvão e adubo diferiu da testemunha. Na avaliação realizada aos 180 dias após o plantio, o tratamento $40 \mathrm{Mg} \mathrm{ha}^{-1}$ de carvão e adubo diferiu da testemunha para os parâmetros $\mathrm{pH}$, acidez potencial, fósforo, cálcio, magnésio, alumínio e umidade do solo. Para os demais parâmetros nessa avaliação não houve diferença significativa.

\section{Efeitos da aplicação dos tratamentos na acidez, nutrientes e umidade do solo}

O aumento dos níveis de bases trocáveis no solo pode elevar o pH do solo pela substituição de íons de $\mathrm{H}$ e $\mathrm{Al}$ no complexo de troca do solo (MIYAZAWA; PAVAN; FRANCHINI, 2000). As maiores doses de biocarvão aplicado aumentaram a quantidade de bases possivelmente pela presença de cinzas na constituição do biocarvão incorporado. Essas cinzas ficam alocadas nos microporos existentes no biocarvão e os cátions trocáveis são adsorvidos por forças eletrostáticas apresentando-se como sais solúveis e consequentemente ficando rapidamente disponíveis para as plantas (SANCHEZ; VILLACHICA; BANDY, 1983; GLASER; LEHMANN; ZECH, 2002). A absorção dos nutrientes pelas plantas, as perdas de íons por lixiviação, a adsorção dos cátions trocáveis no complexo de trocas e, ou a complexação pela matéria orgânica pode ter influenciado a oscilação do $\mathrm{pH}$ quando o nível das bases trocáveis ora aumenta ou diminui no solo de acordo com o tempo após incorporação. Outro aspecto que pode influenciar a elevação do pH do solo é 
a decomposição da matéria orgânica quando há aumento nas bases trocáveis no solo (COSTA et al., 2009; CUNHA et al., 2009), como observado no tratamento $40 \mathrm{Mg} \mathrm{ha}^{-1}$ e adubação. Ainda, a alta reatividade que o biocarvão possui ocasionada pela dissociação dos grupos funcionais presentes nas periferias de suas estruturas podem adsorver íons $\mathrm{H}^{+}$do solo elevando o $\mathrm{pH}$ (MADARI et al., 2006).

Embora as mudanças no $\mathrm{pH}$ do solo apresentadas sejam sutis, Troeh e Thompson (2007) sugerem que em pH ácidos, variações entre 4 e 4,5 podem favorecer a taxa de mineralização da matéria orgânica, reduzir a precipitação do fósforo com $\mathrm{Al}$ e $\mathrm{Fe}$ e diminuir perdas de $\mathrm{Ca}$ e $\mathrm{Mg}$, e $\mathrm{K}$ por lixiviação, acarretando um benefício para áreas de implantação florestal onde o $\mathrm{pH}$ do solo é, normalmente, mais ácido.

A redução significativa da acidez potencial $(\mathrm{H}+\mathrm{Al})$ com a aplicação do biocarvão ocorreu com o tratamento $40 \mathrm{Mg} \mathrm{ha}^{-1}$ e adubação. $\mathrm{O}$ aumento do $\mathrm{pH}$ pode formar espécies de $\mathrm{Al}$ insolúveis e, consequentemente reduz o conteúdo de $\mathrm{H}+\mathrm{Al}$ no solo, além do aumento das bases trocáveis, as quais promovem uma competição pelos sítios de troca, diminuindo o conteúdo de H+Al (VAN RAIJ et al., 1997). Como foi mostrado, o aumento na quantidade de bases trocáveis foi proporcional à quantidade de biocarvão que foi adicionada, pelas maiores quantidades de biocarvão adicionado ao solo conter maior quantidade de cinzas, que disponibilizam cátions para a solução do solo e estes entram em equilíbrio rápido com a superfície de adsorção dos coloides por forças eletrostáticas (GLASER; LEHMANN; ZECH, 2002).

O P total e o disponível se destacam como elementos diagnósticos mais importantes das TPI (PESSOA JUNIOR, 2012) e elevados teores de $\mathrm{P}_{2} \mathrm{O}_{5}$ são encontrados em solos de TPI (SOMBROEK, 1966). Os altos teores de fósforo significativos nos tratamentos devem-se ao fato de que o nutriente realiza ligação orgânica com a matéria orgânica, ficando disponível, o que não ocorre com ligações inorgânicas (argilominerais) nas quais, no solo, o nutriente fica indisponível (MADARI et al., 2006). Além disso, a adição de metais alcalinos, tanto como sais solúveis quanto estes associados aos sítios de troca, em solos com biocarvão, podem ocasionar um efeito significativo na solubilidade do $\mathrm{P}$, especialmente em solos ácidos nos quais as mudanças sutis no $\mathrm{pH}$ podem resultar em substancial redução da precipitação do $\mathrm{P} \operatorname{com~} \mathrm{Al}^{+3} \mathrm{e} \mathrm{Fe}^{+3}$ (DELUCA; MACKENZIE; GUNDALE, 2009).

A cinza presente no biocarvão é predominantemente constituída por óxidos $\left(\mathrm{MgO}, \mathrm{CaO}, \mathrm{K}_{2} \mathrm{O}\right) \mathrm{e}$ devido às reações de dissociação os nutrientes são disponibilizados prontamente para as plantas (SANCHEZ; VILLACHICA; BANDY, 1983). Esse fato justifica o aumento no teor de K no solo aos 60 dias com a aplicação de maiores doses de biocarvão e estes dados corroboram o estudo de Oguntunde et al. (2004). Em geral, grande parte das cinzas de biocarvão é rica em potássio na sua constituição dependendo, principalmente de qual parte do material vegetal foi carbonizado (STEINER; TEIXEIRA; ZECH, 2004). A elevação nos teores das bases trocáveis deve estar relacionada com a constituição do material incorporado, uma vez que, esses valores foram quase sempre superiores à testemunha (K aos 60 dias; $\mathrm{Ca}$ e $\mathrm{Mg}$ aos 180 dias). Segundo Pessoa Junior et al. (2012), na maioria das TPI, os teores de Ca são mais elevados que Mg, $\mathrm{K}$ e Na, pela sua maior disponibilidade advinda dos materiais introduzidos nas áreas de descarte e por sua maior afinidade com as superfícies de troca do solo. Nesse caso, pode ocorrer o fenômeno de complexação da matéria orgânica carbonizada, com íons de cálcio revestindo as partículas do solo. Esse processo pode contribuir para o aumento do nutriente em materiais carbonizados (SOMBROEK, 1966).

Para todos os tratamentos, foi observado que os teores de Mg no solo estavam acima de $2 \mathrm{cmol} /$ $\mathrm{dm}^{3}$. O aumento no teor do nutriente pode estar relacionado com o material de origem dos solos como também com a calagem realizada durante a fase de implantação do experimento. Normalmente, em TPIs, a quantidade de $\mathrm{Mg}$ é menor que $1 / 5$ da quantidade de Ca (SOMBROEK, 1966). A liberação dos íons $\mathrm{Mg}$ ocorreu de forma mais lenta que $\mathrm{K}$ e Ca como observado na Tabela 3, visto que o tratamento $40 \mathrm{Mg}^{-1}$ foi superior à testemunha no último período avaliado para o $\mathrm{Mg}$. Mesmo com diferença estatística nos períodos avaliados para o $\mathrm{Ca}$ e $\mathrm{Mg}$, a relação $\mathrm{Ca} / \mathrm{Mg}$ foi semelhante em todos os tratamentos, evidenciando relação abaixo de 2/1. Esse fato é associado à calagem com calcário dolomítico que elevou o teor de magnésio no solo causando um desbalanço na relação $\mathrm{Ca} / \mathrm{Mg}$.

Alguns mecanismos são relatados para a retenção de nutrientes através do biocarvão, porém, há influência do tipo de biocarvão e da temperatura de pirólise submetida (OJEDA et al., 2015). O carvão pirogênico pode apresentar uma maior densidade de carga negativa por unidade de área superficial e consequentemente uma maior densidade de carga, devido às características químicas desejáveis do biocarvão (LIANG et al., 2006). A retenção de nutrientes nas partículas dos materiais carbonizados também se deve ao fato de 
que os mesmos são presos através de forças físicas nos poros finos do biocarvão (GLASER; LEHMANN; $\mathrm{ZECH}, 2002$ ). Em suma, nenhum desses fatores atua de forma isolada pois, há um grande número de reações que podem ocorrer em nível de solução do solo e matéria orgânica e, portanto, todos os processos para a retenção de nutrientes podem acontecer ao mesmo tempo. Na Austrália, foi realizado um estudo com vistas à produção de milho (Zea mays) sob influência de diferentes doses de biocarvão de resíduos da produção de tomates verdes obtidos por pirólise lenta $\left(>550^{\circ} \mathrm{C}\right)$, em dois tipos de solos, um arenoso pouco desenvolvido semelhante aos Neossolos quartzarênicos, e outro muito argiloso rico em óxidos e hidróxidos de Fe e Al com alta CTC onde, os autores atribuíram ao alto teor de cinzas a maior disponibilidade de N, P, $\mathrm{K}, \mathrm{S}, \mathrm{Ca}$ e $\mathrm{Mg}$ do que a maioria dos outros biocarvões convencionais. Os resultados, entretanto, mostraram queda na produção de massa seca nos solos jovens arenosos, fato atribuído ao excesso de sais solúveis na solução no solo como também a concentração de hidroxilas, devido à alta alcalinidade do biocarvão que, por sua vez, causou fitotoxidez nas plantas, contrapondo com os resultados nos solos argilosos com $\mathrm{pH}$ ácido, em que a capacidade trocável do solo reduziu as concentrações de sais solúveis na solução do solo proporcionando efeitos positivos diretos e indiretos na produção de milho (SMIDER; SINGH, 2014).

Os valores de $\mathrm{Al}$ diminuíram com o aumento da quantidade de biocarvão incorporado, o que pode ser justificado pela precipitação do alumínio que é favorecida com a elevação do $\mathrm{pH}$ formando $\mathrm{Al}(\mathrm{OH})_{3}$, diminuindo sua atividade na solução do solo e consequentemente a sua toxidez (ERNANI, 2008). Esses dados estão de acordo com a discussão sobre a elevação dos níveis de bases trocáveis no solo através dos conteúdos maiores de biocarvão. Além deste fato, ainda pode ocorrer, em determinados tipos de biocarvão, a capacidade de redução de concentrações de metais pesados em solos contaminados. Puga et al. (2015) avaliando o potencial do biocarvão de palha de cana-de-açúcar no desenvolvimento de Canavalia ensiformis e Mucuna aterrima em solos contaminados, verificaram que houve menor absorção de metais pesados pelas culturais bem como incremento na fitomassa e disponibilidade significativa de P, entretanto, esse efeito mitigador deve ser melhor avaliado uma vez que os metais pesados podem acumular-se nos tecidos das plantas.

A matéria orgânica do solo pode governar a geração de cargas elétricas negativas sob dependência do $\mathrm{pH}$, todavia, essas cargas não foram expressivas devido à baixa quantidade de material orgânico nos solos, cerca de $4 \%$ em relação à massa mineral, água e espaços porosos. O aumento do $\mathrm{pH}$ e o número de bases adicionadas nos tratamentos com as maiores doses não foram suficientes para elevar a CTC em relação à testemunha e adubação, porque ocorreu também diminuição da acidez potencial e precipitação do $\mathrm{Al}^{3+}$ na forma de óxidos pouco solúveis.

O teor de carbono orgânico do solo nos tratamentos com biocarvão deveria ter sido superior ao da testemunha, fato que não foi observado nesse estudo. O biocarvão adicionado apresentava cerca de $48 \%$ de carbono fixo. Assim, os teores de carbono deveriam aumentar cerca de 5, 10 e $20 \mathrm{~g} / \mathrm{dm}^{3} \mathrm{com}$ a adição de 10,20 e $40 \mathrm{Mg} \mathrm{ha}^{-1}$ de biocarvão, respectivamente. Porém, o maior aumento observado foi de $1,8 \mathrm{~g} / \mathrm{dm}^{3} \mathrm{em}$ relação à testemunha (Tabela 3). Madari et al. (2006) relataram que o método para a quantificação de matéria orgânica do solo baseado na oxidação por dicromato de potássio (Walkley-Black) apenas quantifica a matéria orgânica oxidável do solo e, como o biocarvão é muito estável, este método não o quantifica devido à difícil digestão com ácido sulfúrico concentrado (STEINER; TEIXEIRA; ZECH, 2004).

O biocarvão possui uma estrutura muito porosa que pode ter a função de retenção da água do solo, funcionando como "esponja", aumentando a disponibilidade de água potencial para as plantas. Muitos trabalhos mostram que a disponibilidade de água para as plantas depende basicamente da textura, estrutura e teor de matéria orgânica do solo. Desta forma, a matéria orgânica incorporada no solo na forma de biocarvão pode ter atuado de forma positiva com a fração mineral melhorando as propriedades físico-hídricas, formando agregados, reduzindo a coesão e a plasticidade além de contribuir para o arejamento e friabilidade do solo acumulando mais água no solo (PICCOLO; PIETRAMELLARA; MBAGWU, 1997; BENITES et al., 2009; COSTA et al., 2009).

O aumento da umidade do solo pode estar relacionado com a textura dos solos (OJEDA et al., 2015). A elevação da umidade em solos muito argilosos propõe um efeito combinando entre o biocarvão e a parte mineral do solo. Esses resultados contrapõem os resultados encontrados por Sohi et al. (2010) que afirmam que o tamanho dos poros do biocarvão é relativamente fixo, enquanto que a do solo mineral é determinada principalmente pela textura, assim pode-se esperar que os acréscimos da umidade a partir do biocarvão são 
maiores em solos arenosos, tem um efeito neutro em solos de textura média, e diminui a umidade disponível no solo argiloso. Tryon (1948), citado por Glaser, Lehmann e Zech (2002) encontrou 18\% de acréscimos na retenção da umidade do solo em relação a quantidade de biocarvão em solos arenosos, entretanto não houve variação da umidade em solos argilosos e siltosos devido à hidrofobicidade do biocarvão.

O biocarvão é um material naturalmente hidrofóbico e isto propicia pouca ou nenhuma absorção de água, entretanto, essa característica pode ter sido modificada, devido às condições que o biocarvão sofreu antes da incorporação, ou seja, exposição ao tempo, precipitações e temperatura. Neste trabalho, a aplicação de $40 \mathrm{Mg} \mathrm{ha}^{-1}$ ocasionou maior capacidade de retenção de água num solo de textura muito argilosa. Em solos de textura média a argilosa, que possuem naturalmente quantidade maior de microporos para a retenção de quantidades maiores de água, o biocarvão pode interferir neste atributo, elevando ainda mais o teor água no solo. Além disso, outro aspecto que interfere na disponibilidade de água no solo é o regime de chuvas e foi observado um déficit hídrico no período das coletas de solo, com menos de 100 e $70 \mathrm{~mm}$.mês ${ }^{-1}$ (Tabela 1) aos 60 e 180 dias, respectivamente, considerado normal para a época do ano e tornando importante a influência do biocarvão no aumento da umidade do solo. Ojeda et al. (2015) relataram que o fluxo de água é bastante afetado pelo tipo do biocarvão, concluindo que a mistura de biocarvão com lodo de esgoto favoreceu a maior liberação de nutrientes, principalmente $\mathrm{Ca}$ e $\mathrm{S}$, além da umidade do solo. Os autores ainda ressaltaram que os efeitos da aplicação de biocarvão devem ser monitorados em solos instáveis, uma vez que pode ocorrer a maior liberação de nutrientes no contato solo-água provocando alterações nos ecossistemas aquáticos por processos de eutrofização (excesso de $\mathrm{N}$ e $\mathrm{P}$ em corpos hídricos).

\section{CONCLUSÕES}

A aplicação de $40 \mathrm{Mg} \mathrm{ha}^{-1}$ de biocarvão com e sem adubação de base elevou os teores de bases trocáveis $(\mathrm{K}, \mathrm{Ca} \mathrm{e} \mathrm{Mg})$ e $\mathrm{P}$ no solo devido à maior presença de cinzas na constituição do biocarvão, e com isso houve o aumento do pH do solo e a redução do $\mathrm{Al}$ e da acidez potencial aos 60 e 180 dias após a incorporação do biocarvão.

A aplicação de $40 \mathrm{Mg} \mathrm{ha}^{-1}$ de biocarvão elevou o teor de água no solo em relação à testemunha nos períodos avaliados independentemente do regime de chuvas, indicando que, em solos argilosos, a aplicação do biocarvão contribui para retenção de água.

Embora a aplicação de $40 \mathrm{Mg} \mathrm{ha}^{-1}$ de biocarvão tenha sido superior à testemunha nos períodos analisados, a dose intermediária de $20 \mathrm{Mg} \mathrm{ha}^{-1}$ foi similar na disponibilidade de cátions básicos e redução do pH e acidez solo, principalmente aos 180 dias após a incorporação. Portanto, a aplicação de biocarvão pode se tornar uma prática positiva com o objetivo de disponibilizar nutrientes para o desenvolvimento inicial da cultura. Contudo, deve-se a avaliar o efeito da fertilidade de acordo com as doses aplicadas a longo prazo, uma vez que, a disponibilidade de nutrientes diminuiu devido à absorção das plantas e neste caso ocasiona a necessidade de adubações de cobertura, porém em quantidades menores que o necessário para a cultura, com a aplicação do biocarvão.

\section{AGRADECIMENTOS}

Os autores agradecem à Coordenação de Aperfeiçoamento de Pessoal de Nível Superior (CAPES) pela concessão de bolsa de pós-graduação ao primeiro autor.

\section{REFERÊNCIAS}

BENITES, V. M. et al. Utilização de carvão e subprodutos da carbonização vegetal na agricultura: aprendendo com as Terras Pretas de Índio. In: TEIXEIRA, W. G. et al. (Ed.). As terras pretas de índio da Amazônia: sua caracterização e uso deste conhecimento na criação de novas áreas. 1. ed. Manaus: Embrapa Amazônia Ocidental, 2009. p. 285-296.

COSTA, J. A. et al. Geoquímica das Terras Pretas Amazônicas. In: TEIXEIRA, W. G. et al. (Ed.). As terras pretas de índio da Amazônia: sua caracterização e uso deste conhecimento na criação de novas 
áreas. 1. ed. Manaus: Embrapa Amazônia Ocidental, 2009. p. 162 -172.

CUNHA, T. J. F. et al. Soil organic matter and fertility of anthropogenic dark earths (Terra Preta de Indio) in the Brazilian amazon basin. Revista Brasileira de Ciência do Solo, Viçosa, MG, v. 33, p. 85-93, 2009. DELUCA, T. H.; MACKENZIE, M. D.; GUNDALE, M. J. Biochar effects on soil nutrient transformation. In: LEHMANN J.; JOSEPH S. (Ed.). Biochar for Environmental Management: Science and Technology. London: Earthscan, 2009. p. 251-270.

EMBRAPA. Centro Nacional de Pesquisa de Solos. Manual de métodos de análise de solos. Rio de Janeiro, 1997. 212 p.

EMBRAPA. Centro Nacional de Pesquisa de Solos. Sistema brasileiro de classificação de solos. 2. ed. Rio de Janeiro: EMBRAPA, 2006. 306 p.

ERNANI, P. R. Química do solo e disponibilidade de nutrientes. Lages: O autor, 2008. 230 p.

GLASER, B.; LEHMANN, J.; ZECH, W. Ameliorating physical and chemical properties of highly weathered soils in the tropics with charcoal - a review. Biology and Fertility of Soils, Berlin, v. 35, n. 4, p. 219-230, 2002.

HOSSAIN, M. K. et al. Agronomic properties of wastewater sludge biochar and bioavailability of metals in production of cherry tomato (Lycopersicon esculentum). Chemosphere, Oxford, v. 78, n. 9, p. 1167-1171, 2010.

LEHMANN, J.; JOSEPH, S. Biochar for environmental management: an introduction. In: LEHMANN, J; JOSEPH, S. (Ed.). Biochar for environmental management: science and technology. London: Earthscan, 2009. p. 1-12.

LEHMANN, J.; RONDON. M. Bio-Char soil management on highly weathered soils in the humid tropics. In: UPHOFF, N. et al. (Ed.). Biological approaches to sustainable soil systems. Florida: CRC Press, 2006. p. $517-530$.

LIANG, B. et al. Black carbon increases cations exchange capacity in soils. Soil Science Society of America Journal, Madison, v. 70, p. 1719-1730, 2006.

MADARI, B. E. et al. Carvão vegetal como condicionador do solo para arroz de terras altas (cultivar Primavera): um estudo prospectivo. Comunicado técnico Embrapa Arroz e Feijão, Santo Antônio de Goiás, v. 125, p. 6, 2006.

MAIA, C. M. B. F. Biochar: uma nova ferramenta no manejo de solos. In: SEMINÁRIO DE ATUALIZAÇÃO FLORESTAL, 2.; SEMANA DE ESTUDOS FLORESTAIS, 11., 2012, Irati. Anais... Irati: Universidade Estadual do Centro-Oeste, 2012.

MEDEIROS JUNIOR, J. C. Uso do fino do carvão vegetal e da adubação potássica na produção de berinjela (Solanum melongena L.) em Latossolo amarelo antrópico da Amazônia Central. 2007. 72 f. Dissertação (Mestrado em Biologia Tropical e Recursos Naturais) - Universidade Federal do Amazonas, Manaus, 2007.

MIYAZAWA, M.; PAVAN, M. A.; FRANCHINI, J. C. Neutralização da acidez do perfil do solo por resíduos vegetais. Informações Agronômicas Potafos, Piracicaba, n. 92, p. 8, 2000.

OGUNTUNDE, P. G. et al. Effects of charcoal production on maize yield, chemical properties and texture of soil. Biology and Fertility of Soils, Berlin, v. 39, p. 295-299, 2004.

OJEDA G. et al. Are soil-water functions affected by biochar application? Geoderma, Amsterdam, v. 249, p. 1-11, 2015.

OLIVEIRA, J. B. Estudos preliminares de normatização de testes de controle de qualidade do carvão vegetal. In: PENEDO, W. R. Carvão Vegetal. Belo Horizonte: CETEC, 1982. p. 7-38. (Publicação Técnica CETEC, v. 6).

PESSOA JUNIOR, E. S. F. et al. Terra Preta de Índio na Região Amazônica. Scientia Amazonia, Manaus, v. 1, n.1, p. 1-8, 2012.

PETTER, F.A. Biomassa carbonizada como condicionador de solo: aspectos agronômicos do seu uso em solos de Cerrado. 130 f. Tese (Doutorado em Ciências Agrárias) - Universidade Federal de Goiás, Goiânia, 2010.

PICCOLO, A.; PIETRAMELLARA, G.; MBAGWU, J. S. C. Use of humic substances as soil conditioners to increase aggregate stability. Geoderma, Amsterdam, v. 75, p. 267-277, 1997.

PUGA A. P. et al. Biochar application to a contaminated soil reduces the availability and plant uptake of

Ci. F1., v. 28, n. 4, out. - dez., 2018 
zinc, lead and cadmium. Journal of Environmental Management, New York, v. 159, p. 86-93, 2015.

SANCHEZ, P. A.; VILLACHICA, J. H.; BANDY, D. E. Soil fertility dynamics after clearing a tropical rainforest in Peru. Soil Science Society of America Journal, Madison, v. 47, p. 1171-1178, 1983.

SECRETARIA DO ESTADO E DO ABASTECIMENTO DO PARANÁ. Precipitações mensais nos últimos 12 meses (nov. 2009 - nov. 2010). Curitiba: SEAB, 2011. Disponível em: $<$ http://www.seab.pr.gov.br>. Acesso em: 01 fev. 2010.

SILVA, F. A. S.; AZEVEDO, C. A. V. Versão do programa computacional Assistat para o sistema operacional Windows. Revista Brasileira de Produtos Agroindustriais, Campina Grande, v. 4, n. 1, p. 71-78, 2002.

SMIDER B.; SINGH B. Agronomic performance of a high ash biochar in two contrasting soils. Agriculture, Ecosystems \& Environment - Journal, Amsterdam, v. 191, p. 99-107, 2014.

SOHI, S. P. et al. A review of biochar and its use and function in soil. Advances in Agronomy, Burlington, v. 105, p. 47-82, 2010.

SOMBROEK, W. G. Amazon soils: A reconnaissance of the soils of the Brazilian Amazon region. Wageningen: Centre for Agricultural Publication and Documentation, 1966. 292 p.

STEINER, C.; TEIXEIRA, W. G.; ZECH, W. Slash and char: an alternative to slash and burn practiced in the Amazon basin. In: GLASER, B. B. E WOODS, W. I. (Ed.). Amazonian dark earths: explorations in space and time. Berlin: Springer Verlag, 2004. p. 183-194.

TROEH, F. R.; THOMPSON, L. M. Solos e fertilidade do solo. São Paulo: Andrei, 2007. 718 p.

TRYON, E. H. Effects of charcoal on certain physical, chemical, and biological properties of forest soils. Ecological Monographs, Ithaca, New York, v. 18, n. 1, p. 81-115, 1948.

VAN RAIJ, B. et al. Recomendações de adubação e calagem para o estado de São Paulo. Boletim Técnico IAC, Campinas, n. 100, 285 p. 1997. 